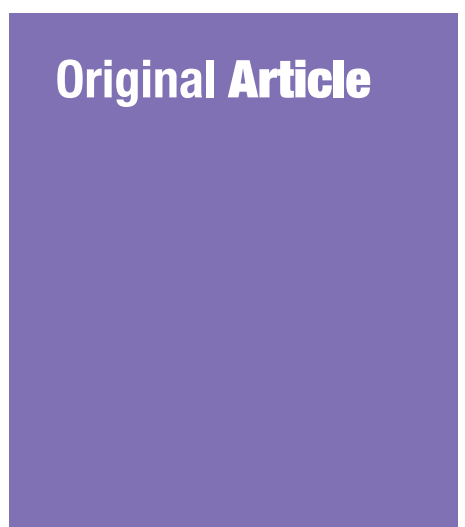

Submitted: 28 Feb 2017 Accepted: 23 Apr 2017 Online: 30 Jun 2017

\section{Achievement of LDL Cholesterol Goal and Adherence to Statin by Diabetes Patients in Kelantan}

\author{
Zainab Mat Yudin 1 , LILI Husniati Yaacob ${ }^{1}$, Norul Badriah \\ Hassan ${ }^{2}$, SAIFUl BAHARI Ismail', NANI Draman', SITI SUHAILA \\ Mohd Yusoff ${ }^{1}$
}

Department of Family Medicine, School of Medical Sciences, Universiti Sains Malaysia 16150 Kubang Kerian, Kelantan, Malaysia

Department of Pharmacology, School of Medical Sciences, Universiti Sains Malaysia, 16150 Kubang Kerian, Kelantan, Malaysia

To cite this article: Zainab MY, Lili Husniati Y, Norul Badriah H, Saiful Bahari I, Nani D, Siti Suhaila MY. Achievement of LDL cholesterol goal and adherence to statin by diabetes patients in Kelantan. Malays J Med Sci. 2016;24(3):4450. https://doi.org/10.21315/mjms2016.24.3.6

To link to this article: https://doi.org/10.21315/mjms2016.24.3.6

\title{
Abstract
}

Background: Statins are a class of potent drugs that can be used to reduce cholesterol, especially low-density lipoprotein cholesterol (LDL-C). However, their effectiveness is limited if adherence to treatment is poor. The objectives of the study are to estimate the proportion of diabetic patient who has achieved LDL-C goal and to determine the association of LDL-C achievement with socio demographic factors and statin therapy adherence

Methods: This is a cross-sectional study involving 234 patients with type 2 diabetes mellitus (T2DM) and dyslipidaemia attending an outpatient clinic in a hospital in Kelantan. Interviews and self-administered questionnaires were used to determine their sociodemographic and clinical characteristics. Adherence to therapy was assessed using the Medication Compliance Questionnaire (MCQ). The associations between the achievement of LDL targets and sociodemographic/clinical factors, including adherence, were analysed with simple logistic regression.

Results: About 37.6\% of patients achieved their LDL-C target. The percentage of patients who adhered to statin use was $98.3 \%$, and $20.5 \%$ of these patients reported full adherence. There was no significant association between achievement of LDL-C targets with adherence or any other sociodemographic factors, such as age, gender and educational or economic status (all $P$-value $<$ 0.05).

Conclusion: Despite a high level of adherence, the majority of patients failed to achieve LDL-C targets. More concerted efforts are needed to improve this.

Keywords: low-density lipoprotein cholesterol, adherence, statin, diabetes 
Original Article | LDL-C target and adherence in diabetes patient

\section{Introduction}

Dyslipidaemia and diabetes mellitus are major predictors of cardiovascular disease because both clinical condition have an effect on macrovascular disease and artherogenesis (1). Individuals with both clinical conditions are considered to be at a higher risk of developing cardiovascular disease, and reaching treatment targets is important in preventing further morbidity and mortality resulting from cardiovascular events. The National Cholesterol Education Programme-Adult Treatment Plan I to III (NCEP-ATP III) has established LDL cholesterol as a primary target for therapeutic interaction because low-density lipoprotein cholesterol (LDL-C) plays a major role in initiating the development of atherosclerotic plaque (2).

Adherence to lipid lowering therapy, particularly for the statin group, which contains the most potent antilipids in terms of reducing LDL-C level, is very important. Non-adherence to medications is common for patients with chronic illnesses, such as cardiovascular disease, diabetes, hypertension and dyslipidaemia. According to the World Health Organisation, non-adherence to long-term medication use for conditions such as hypertension, dyslipidaemia and diabetes is a common problem that leads to compromised health benefits and serious economic consequences in term of wasted time and money and uncured diseases (3). Primary care patients' non-adherence to statin medications was evaluated, and the results showed a low rate of non-adherence, 37\% (4). Another study conducted at a different primary care setting found approximately $51 \%$ patients did not adhere to statin therapy (5).

It is crucial to manage dyslipidaemia, and pharmacological treatment should be initiated once it is indicated. Target blood cholesterol levels are achieved not done through drug therapy but also therapeutic changes in lifestyle. Therefore, being aware of the factors associated with LDL-C target achievement can assist physicians in recognising patients who may fail to achieve their LDL-C targets. Thus, the aim of this study is to estimate the proportion of diabetic patient who has achieved LDL-C goal and to determine the association of LDL-C achievement with sociodemographic factors and statin therapy adherence.

\section{Materials and Methods}

This cross-sectional study was performed from January 2013 to May 2013 among patients with type 2 diabetes mellitus (T2DM) who were on statin therapy. It was conducted at a primary care clinic in Hospital Universiti Sains Malaysia, a tertiary hospital in north-eastern Malaysia. The daily attendance at the outpatient clinic ranges from 200 to 300 patients per day, and it is run by 50 staff members, including family medicine specialists, medical officers, and nurses.

Low-density lipoprotein cholesterol (LDL-C) target achievement is based on the NCEP-ATP III. The achievers of LDL-C targets are those diabetic patients who attained LDL-C levels $<2.6 \mathrm{mmol} / \mathrm{L}$, and LDL-C target nonachievers are those diabetic patients who attained LDL-C levels $\geq 2.6 \mathrm{mmol} / \mathrm{L}$.

\section{Data collection procedure}

The sample size was calculated using a single proportion formula. The absolute precision was set at 0.07 , and the proportion of LDL-C achievers was 0.44 based on Parris et al. (6). The minimum sample size calculated is 193 , and after considering 30\% non-response, the final sample size is 251 .

The inclusion criteria were patients aged 18 years old or above with T2DM who had been on statin therapy for more than six months. The exclusion criteria were illiteracy, a history of mental illness or mental retardation, triglyceride levels of more than $4.3 \mathrm{mmol} / \mathrm{L}$, and unavailable blood results.

Diabetic patients who attended the primary care clinic for routine blood investigation were approached by the researcher based on systematic random sampling of 1 in 2 using the attendance list. Patients fasted for at least eight hours prior to having their blood drawn. The nature of the study was explained, and the informed consent of the patients was obtained. Patients were then given a self-administered, validated compliance questionnaire. All subjects were required to complete the questionnares during that visit. The researcher was present to assist if needed. Once completed, the questionnares were returned to the researcher.

The researcher completed the remaining information needed using the data taken from the patients' online medical records. For each subject of the study, the online blood results and list of medications taken were traced by keying in the patient's hospital registration number 
into the online results database and online prescription database. The results of the blood investigations (lipid profile and $\mathrm{HbA1c}$ ) were taken from the test performed on the day of the interview.

\section{Instruments}

A self-administered questionnaire was used in this study. This Medication Compliance Questionnaire (MCQ) was used to assess patients' adherence to statin therapy. It was developed by Hassan et al. in 2006 to assess adherence to antihypertensive medication (7). The questionnaire has since been modified to suit the study objectives and for use among T2DM patients on statin therapy.

The pre-testing of the questionnaire was conducted among ten patients with T2DM who were on statin therapy and attended Klinik Pakar Perubatan, Hospital USM. The clarity and appropriateness of the questions was analysed. It took about 10-15 minutes for each respondant to complete the set of questions.

There were two sections in the questionnaire. The first section concerned sociodemographic data. These include age, sex, race, marital status, smoking status, occupation, income, and educational level. The second section of the questionnaires concerned the MCQ. It was comprised of a set of ten questions in two domains: a drug-taking behaviour domain, comprised of seven items, and a drugstopping behaviour domain, comprised of three items. The internal consistency reliabilities (Cronbach's alpha values) were 0.67 and 0.84 , and the test-retest single-measure intra-class correlation coefficients were 0.78 and 0.93 (7). The scores were calculated using a Likert scale ranging from 1 to 5 , with 1 indicating 'never' and 5 indicating 'very frequently'. All negatively worded scores were reversed, and all scores were converted to a $0-100$ score. Patients with good compliance or adherence, with a score of 75 or more, answered 'frequently' or 'very frequently' to all items in the questionnaire. Patients who scored less than 75 were considered to be in the non-adherence group. The full-adherence group included those patients who scored 100.

The study protocol received ethical approval from the Ethics Committee of Universiti Sains Malaysia (USMKK/PPP/JEPEM[248.4.1.120]).

\section{Statistical analysis}

Descriptive statistics were used to analyse the sociodemographic and clinical data, and the results were presented as means and frequencies. The association between adherence, sociodemographic and clinical factors and LDL-C target achievement was analysed using simple logistic regression. The significance level was set at a $P$-value $<0.05$, with a $95 \%$ confidence interval. All analyses were performed with the Statistical Package for Social Sciences (SPSS), Version 22.

\section{Results}

A total of 234 patients participated in the study, and the response rate was $93.2 \%$. The socio-demographic characteristics of the respondents are shown in Table 1 . The mean age of the respondents was $59.2 \pm 9.21$ years old. There were almost equal numbers of males and females in the study. The majority of the respondents were Malay. More than half of the respondents $(65.8 \%)$ had completed secondary school.

The clinical characteristics of the patients are shown in Table 2. The majority of the respondents were prescribed four or more medications, and atorvastatin was the most commonly prescribed statin (68.8\%). Half of respondents (50.4\%) had already been on statins for 1 to 5 years. Most of the respondents did not experience any side effects of statin therapy (89.7\%).

The mean BMI, HbA1c, total cholesterol, LDL, triglycerides and HDL values were $26.4 \pm$ $5.30 \mathrm{~kg} / \mathrm{m}^{2}, 7.92 \pm 1.90 \%, 4.89 \pm 1.13 \mathrm{mmol} / \mathrm{L}$, $2.96 \pm 0.96 \mathrm{mmol} / \mathrm{L}, 1.65 \pm 0.73 \mathrm{mmol} / \mathrm{L}$ and $1.23 \pm 0.26 \mathrm{mmol} / \mathrm{L}$, respectively. In terms of statin use, the majority of patients were on atorvastain (68.8\%), and only $10.3 \%$ experienced side effects from statin use.

This study revealed that $37.6 \%$ of patients with T2DM achieved their LDL-C goals. We reported a high rate of adherence to statin therapy, $98.3 \%$ (scores of 75 or above). About $20.5 \%$ of patients fully adhered (score of 100 on the MCQ). Despite the high level of adherence among the study sample, this is not associated with the achievement of LDL-C targets, as shown in Table 3. Furthermore, no sociodemographic factors were significantly associated with the achievement of LDL-C targets. The type of statin used was also found not to be significantly associated with LDL-C target achievement. 
Original Article | LDL-C target and adherence in diabetes patient

Table 1. Socio-demographic characteristic of respondents $(n=234)$

\begin{tabular}{|c|c|c|}
\hline Variables & Mean (SD) & Frequency (\%) \\
\hline Age (Years \pm SD) & $59.2(9.21)$ & \\
\hline $\begin{array}{l}\text { Sex: Male } \\
\quad \text { Female }\end{array}$ & & $\begin{array}{c}103(44.0) \\
131(56.0)\end{array}$ \\
\hline $\begin{array}{r}\text { Race:Malay } \\
\text { Others }\end{array}$ & & $\begin{array}{l}213(91.0) \\
11(9.0)\end{array}$ \\
\hline $\begin{array}{l}\text { Marital status: } \\
\text { Married } \\
\text { Unmarried / widow }\end{array}$ & & $\begin{array}{c}209(89.3) \\
25(10.7)\end{array}$ \\
\hline $\begin{array}{l}\text { Education : } \\
\text { Primary } \\
\text { Secondary } \\
\text { Tertiary }\end{array}$ & & $\begin{array}{c}52(22.2) \\
154(65.8) \\
28(12.0)\end{array}$ \\
\hline $\begin{aligned} \text { Income } & : \leq \mathrm{RM} 700 \\
& >\mathrm{RM} 700\end{aligned}$ & & $\begin{array}{l}116(49.6) \\
118(50.4)\end{array}$ \\
\hline
\end{tabular}

Table 2. Clinical characteristics of the respondents $(n=234)$

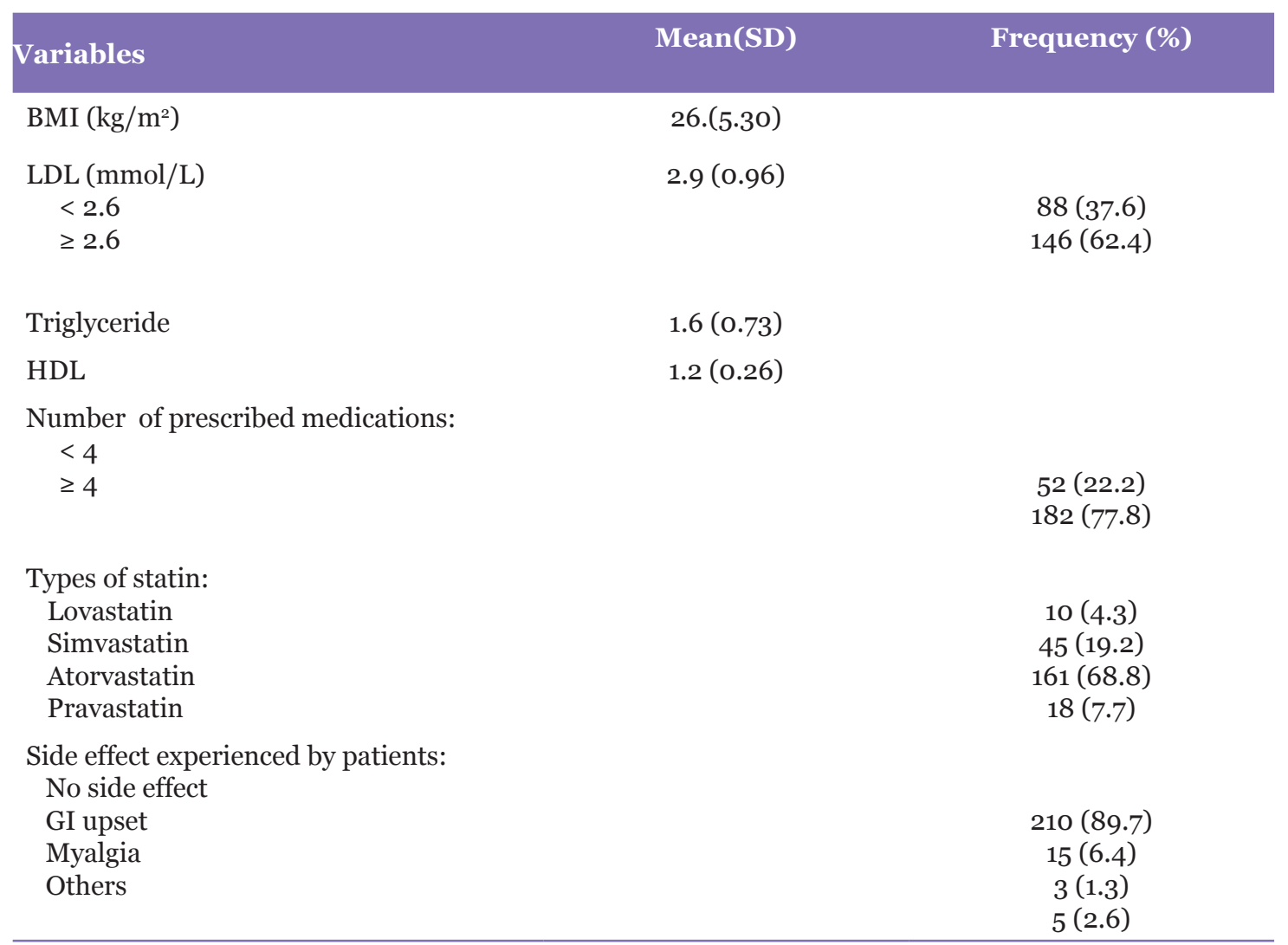


Table 3. Association between sociodemographic/clinical factors and nonachievers of LDL-C target screening by Simple Logistic Regression

\begin{tabular}{|c|c|c|c|c|}
\hline $\begin{array}{c}\text { Sociodemographic } \\
\text { variables }\end{array}$ & $\begin{array}{l}\text { Regression } \\
\text { coefficient }\end{array}$ & Crude OR (95\%CI) & Wald statistic & $P$-value \\
\hline Age (year) & -0.026 & $0.97\left(0.95^{-1.00}\right)$ & 3.005 & 0.083 \\
\hline \multicolumn{5}{|l|}{ Sex } \\
\hline Male & & 1.00 & & \\
\hline Female & 0.167 & $1.18(0.69-2.01)$ & 0.379 & 0.538 \\
\hline \multicolumn{5}{|l|}{ Marital status: } \\
\hline Married & & 1.00 & & \\
\hline Unmarried / widow & 0.077 & $1.08(0.46-2.56)$ & 0.031 & 0.861 \\
\hline \multicolumn{5}{|l|}{ Race: } \\
\hline Malay & & 1.00 & & \\
\hline Nonmalay & 0.205 & $1.23(0.48-3.17)$ & 0.179 & 0.672 \\
\hline \multicolumn{5}{|l|}{ Education: } \\
\hline $\begin{array}{l}\text { No formal education } \\
\text { Primary }\end{array}$ & & 1.00 & 2.940 & 0.401 \\
\hline Secondary & 0.262 & $1.30(0.24-7.14)$ & 0.091 & 0.763 \\
\hline \multirow[t]{2}{*}{ Tertiary } & 0.674 & $1.96(0.38-10.06)$ & 0.652 & 0.419 \\
\hline & 0.143 & $1.15(0.20-6.74)$ & 0.025 & 0.874 \\
\hline \multicolumn{5}{|l|}{ Income: } \\
\hline$\leq \mathrm{RM} 700$ & & 1.00 & & \\
\hline$\geq \mathrm{RM}_{700}$ & -0.191 & $0.83(0.49-1.40)$ & 0.501 & 0.479 \\
\hline $\operatorname{BMI}\left(\mathrm{kg} / \mathrm{m}^{2}\right)$ & -0.039 & $0.96(0.92-1.01)$ & 2.389 & 0.122 \\
\hline \multicolumn{5}{|l|}{ Types of statin: } \\
\hline Lovastatin & & 1.00 & 2.485 & 0.448 \\
\hline Simvastatin & 0.405 & $1.500(0.38-5.94)$ & 0.334 & 0.563 \\
\hline Atorvastatin & 0.494 & $1.639(0.456-5.89)$ & 0.573 & 0.449 \\
\hline Pravastatin & 1.253 & $3.500(0.66-18.50)$ & 2.175 & 0.140 \\
\hline \multicolumn{5}{|l|}{ Adherence to statin therapy: } \\
\hline Adhered & & 1.00 & 4.030 & 0.133 \\
\hline \multirow[t]{2}{*}{ Non-adhered } & 0.636 & $1.89(0.99-3.59)$ & 3.759 & 0.053 \\
\hline & 1.099 & $3.00(0.29-30.90)$ & 0.852 & 0.356 \\
\hline
\end{tabular}

\section{Discussion}

We reported a high rate of adherence to statin therapy, $98.3 \%$. About $20.5 \%$ of patients adhered fully (scores of 100 on the MCQ). This reflected the fact that our population had a better adherence rate to lipid-lowering therapy as compared to other treatments for chronic illnesses such as diabetes or hypertension (6). This study revealed a very low non-adherence rate to statin therapy, which was $1.7 \%$ among patients with dyslipidaemia and T2DM. This figure was extremely low compared to those found in other studies, which have recorded non-adherence rates ranging from $37 \%$ to $51 \%(4,5,8)$. These differing results could be due to the different methods or tools used in assessing adherence. Interviews and all selfreport methods are vulnerable to overestimates of compliance and underestimates of noncompliance (9). According to Casula et al. (10), the adverse effects of statins were among the important causes of non-adherence. They reported that $30 \%$ to $62 \%$ statin therapy discontinuations were due to the side effects of statins. This is in contrast to our study, in which only $10.2 \%$ of patients experienced side effects from statin therapy, and $3.8 \%$ of respondents had a history of discontinuing statins due to their side effects. This indicates a high tolerance of statins, and could be one of the factors contributing to the high level of adherence in our study. 
Original Article | LDL-C target and adherence in diabetes patient

Globally, LDL-C goal achievement ranges from $18 \%$ to $73 \%$, but this wide range may be due to differences in the studied populations (4, 11-14). However, our findings showed a lower percentage, $37.6 \%$, as compared to a large multinational patient population study involving nine countries, which found $67 \%$, $74 \%$ and $86 \%$ achievement of LDL-C goals in high-risk, moderate-risk and low-risk patients, respectively (15). Mafauzy et al. (16) conducted a DiabCare Malaysia 2008 project and assessed the management of diabetes in general hospitals, diabetes clinics and referral clinics throughout the country. They discovered that $54 \%$ of diabetic patients had LDL-C $<2.6 \mathrm{mmol} / \mathrm{L}$. A local diabetic audit by Shariff et al. (17) examined two urban public primary care clinics in Malaysia and revealed a very low level of LDL-C target achievement, $13.0 \%$.

It is a surprise that despite the high adherence rate, the level of LDL-C target achievement was still low in our population. This could be due to several factors that were not investigated in this study. It is possible that the physician-treatment strategy has contributed to the low level of LDL target achievement. Hwang et al. (18) noted that the failure of physicians to titrate the dose of statins and their ignorance of target levels were among the factors contributing to the low achievement of LDL-C targets. Another factor that could affect lipid level is patients' lifestyles. The physical activity and dietary patterns of the subjects could have contributed to the low level of target achievement seen in this study. Unfortunately, this factor was not addressed in our study.

This study has several limitations. Major factors that can influence cholesterol level, such as dietary pattern and physical activity, are not assessed in this study. This study only explored the sociodemographic and clinical factors. The data represent only one outpatient clinic in a tertiary centre, rather than involving other outpatient clinics in other tertiary centres or other primary health clinics in other districts or states. Therefore, the results of the study are not representative of the entire population. This study used a self-reported measurement of adherence, which might be lead to over-reporting or under-reporting. Thus, the actual proportion of non-adherence to statin therapy may be higher than that revealed in this study. Finally, this study used univariable analysis which can be biased. Whenever possible, multivariable analysis should be performed.

\section{Conclusion}

In conclusion, we found that the achievement of LDL-C target was still low in our community despite the high adherence rate to statin therapy. Therefore physicians need to have more comprehensive efforts to ensure better outcome in the management of both diabetes and dyslipidaemia in order to reduce the cardiovascular morbidity and mortality.

\section{Authors' Contributions}

Conception and design: ZMY, LHY, NBH, SBI, ND, SSMY

Analysis and interpretation of the data: ZMY, LHY

Drafting of the article: ZMY, LHY, NBH, SBI, ND, SSMY

Critical revision of the article for important intellectual content: ZMY, LHY, NBH, SBI, ND, SSMY

Final approval of the article: ZMY, LHY, NBH, SBI, ND, SSMY

Collection and assembly of data: ZMY

\section{Correspondence}

Dr Lili Husniati Yaacob

MBBS (University of Adelaide), MMed Family Medicine (USM)

Department of Family Medicine

School of Medical Sciences

Universiti Sains Malaysia

16150 Kubang Kerian,

Kelantan, Malaysia

Tel: 6097676613

Fax: 6097653370

E-mail: husniati@usm.my

\section{References}

1. John Betteridge D. Dyslipidaemia and diabetes. Practical Diabetes International. 2001;18(6):201-207. https://doi.org/10.1002/ pdi.231

2. Academy of Medicine of Malaysia. Clinical practice guideline 4th edition: Management of Dyslipidaemia 2011. Ministry of Health, Malaysia; 2011. 
3. World Health Organization. Adherence to longterm therapies: evidence for action. 2003. Retrieved August 28, 2014 from http://apps.who. int/medicine/en/d/Js4883e/6.1.3.html

4. Natarajan N, Putnam RW, Yip AM, Frail D. Family practice patients' adherence to statin medications. Canadian Family Physician. 2007;53(12):2144-2145.

5. Bermingham M, Hayden J, Dawkins I, Miwa S, Gibson D, McDonald K, et al. Prospective analysis of LDL-C goal achievement and selfreported medication adherence among statin users in primary care. Clinical Therapeutics. 2011;33(9):1180-1189. https://doi.org/10.1016/j. clinthera.2011.07.007

6. Parris ES, Lawrence DB, Mohn LA, Long LB. Adherence to statin therapy and LDL cholesterol goal attainment by patients with diabetes and dyslipidemia. Diabetes Care. 2005;28(3):595599. https://doi.org/10.2337/diacare.28.3.595

7. Hassan NB, Hasanah C, Foong K, Naing L, Awang $\mathrm{R}$, Ismail SB, et al. Identification of psychosocial factors of noncompliance in hypertensive patients. J Hum Hypertens. 2005;20(1):23-29. https:// doi.org/10.1038/sj.jhh.1001930

8. Cramer J, Benedict A, Muszbek N, Keskinaslan A, Khan Z. The significance of compliance and persistence in the treatment of diabetes, hypertension and dyslipidaemia: a review. Int $J$ Clin Pract. 2008;62(1):76-87. https://doi. org/10.1111/j.1742-1241.2007.01630.x

9. Vermeire E, Hearnshaw H, Van Royen P, Denekens J. Patient adherence to treatment: three decades of research. A comprehensive review. $J$ Clin Pharm Ther. 2001;26(5):331-342. https:// doi.org/10.1046/j.1365-2710.2001.00363.x

10. Casula M, Tragni E, Catapano AL. Adherence to lipid-lowering treatment: the patient perspective. Patient Prefer Adherence. 2012;6:805.

11. Waters DD, Brotons $\mathrm{C}$, Chiang $\mathrm{C}-\mathrm{W}$, Ferrières J, Foody J, Jukema JW, et al. Lipid treatment assessment project 2: A multinational survey to evaluate the proportion of patients achieving lowdensity lipoprotein cholesterol goals. Circulation. 2009;120(1):28-34. https://doi.org/10.1161/ CIRCULATIONAHA.108.838466
12. Khateeb AA, Mohamed MS, Imran K, Ibrahim S. Low density lipoprotein cholesterol goal attainment among Malaysian dyslipidemic patients. Southeast Asian J Trop Med Public Health. 2011;42(2).

13. Kauffman AB, Olson KL, Youngblood ML, Zadvorny EB, Delate T, Merenich JA. Attainment of low-density lipoprotein cholesterol goals in coronary artery disease. $J$ Clin Lipidol. 2010;4(3):173-180. https://doi.org/10.1016/j. jacl.2010.03.002

14. Afonso NM, Nassif G, Aranha A, DeLor B, Cardozo LJ. Low-density lipoprotein cholesterol goal attainment among high-risk patients: Does a combined intervention targeting patients and providers work? Am $J$ Manag Care. 2006;12(10):589-594.

15. Santos RD, Waters DD, Tarasenko L, Messig M, Jukema JW, Chiang C-W, et al. A comparison of non-HDL and LDL cholesterol goal attainment in a large, multinational patient population: The lipid treatment assessment project 2 . Atherosclerosis. 2012;224(1):150-153. https:// doi.org/10.1016/j.atherosclerosis.2012.06.052

16. Mafauzy M, Hussein Z, Chan S. The status of diabetes control in Malaysia: results of DiabCare 2008. Med J Malaysia. 2011;66(3):175-181.

17. Shariff Ghazali S, Abu Hassan Z, Ali Z, Ian O. A clinical audit on diabetes care in two urban public primary care clinics in Malaysia. Malaysian Journal of Medicine and Health Sciences. 2010;6(1):101-109.

18. Hwang JY, Jung CH, Lee WJ, Park CY, Kim SR, Yoon $\mathrm{K}$, et al. Low density lipoprotein cholesterol target goal attainment rate and physician perceptions about target goal achievement in Korean patients with diabetes. Diabetes Metab J. 2011;35(6):628-636. https://doi.org/10.4093/ dmj.2011.35.6.628 